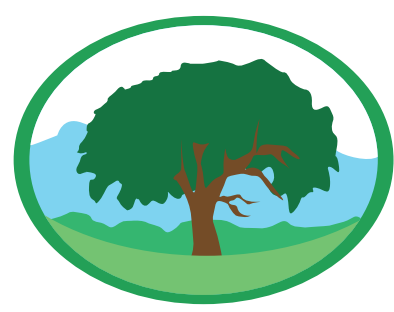

\title{
VIABILIDADE TÉCNICA E ECONÔMICA DA IMPLANTAÇÃO DE UMA AGROINDUSTRIA DE EXTRATO VEGETAL
}

LIMA, L. D. S. C. ${ }^{1}$; LUZ, M. L. G. S. ${ }^{2}$; LUZ, C. A. S. ${ }^{3}$; GADOTTI, G. I. ${ }^{4}$; MALDANER, V. ${ }^{5}$; SANTOS, J. B. ${ }^{5}$;

BERNARDY, R. ${ }^{6}$

'Engenheira agrícola

${ }^{2}$ Professora titular, Centro de Engenharias, Universidade Federal de Pelotas

${ }^{3}$ Professor titular, Centro de Engenharias, Universidade Federal de Pelotas

${ }^{4}$ Professora adjunta, Centro de Engenharias, Universidade Federal de Pelotas

${ }^{5}$ Graduanda do curso de Engenharia Agrícola, Centro de Engenharias, Universidade Federal de Pelotas

${ }^{6}$ Graduando do curso de Engenharia Agrícola, Centro de Engenharias, Universidade Federal de Pelotas

Palavras-chave: análise sensorial, estudo de mercado, viabilidade econômica, nozpecã

\begin{abstract}
Resumo
Estima-se que aproximadamente 15,2 milhões de brasileiros sejam vegetarianos, o que corresponde a $8 \%$ da população do país. Neste sentido, as bebidas de base vegetal surgem como alternativa de produto alimentício para vegetarianos e veganos, bem como para alérgicos à proteína do leite e intolerantes à lactose. Este trabalho teve o objetivo de analisar a viabilidade técnica e econômica de uma agroindústria que produza dois tipos de extrato vegetal: de noz-pecã e de amendoim. Nesse estudo, foi computado o mercado consumidor relativo à quantidade para dimensionar a agroindústria e foi realizado um teste de análise sensorial para orientar a formulação do extrato. A análise econômica do projeto mostrou que a proposta é viável, com retorno do capital investido em 4 ou 6 anos, para os cenários estudados.
\end{abstract}

\section{TECHNICAL AND ECONOMIC FEASIBILITY IN AN AGRO-INDUSTRY OF VEGETABLE MILK}

Keywords: sensory analysis, market research, economic analysis, pecan nut

\begin{abstract}
It is estimated that approximately 15.2 million Brazilians are vegetarians, corresponding to $8 \%$ of the country's population. In this sense, vegetable-based drinks are an alternative food product for vegetarians and vegans, as well as for milk protein allergy and lactose intolerant. This work aimed to analyze the technical and economic viability of an agroindustry that produces two types of plant extract: pecan nut and peanut. In this study, the consumer market was computed regarding the quantities to size the agribusiness and a sensorial analysis test was conducted to guide the formulation of the extract. The economic analysis of the project showed that the proposal is viable, with return of capital invested in 4 or 6 years, for the scenarios studied.
\end{abstract}




\section{INTRODUÇÃO}

O extrato vegetal é um produto procurado por pessoas que seguem dietas alimentares como vegetarianismo, veganismo, este que exclui qualquer produto que gere exploração e/ou sofrimento animal, ou seja, não há consumo de carnes, ovos, laticínios, mel etc. Também por pessoas com alergias à proteína do leite e intolerantes à lactose, que, segundo a Federação Brasileira de Gastroenterologia (FBG) (2017), esta intolerância ocorre quando há sintomas gastrointestinais associados à má digestão de lactose, sendo que no Brasil estes sintomas ocorrem em até $50 \%$ da população.

Neste sentido, as bebidas de base vegetal (popularmente conhecidas como "leite vegetal") são uma alternativa ao leite de vaca a essas pessoas, porém há uma carência de sabores em marcas comerciais, além do alto custo destes produtos encontrados no mercado.

A formulação do extrato vegetal é ajustada conforme as condiçóes de processamento da agroindústria e preferências do consumidor. O processo de obtenção do extrato vegetal é relativamente simples e de baixo custo (EMBRAPA, 2005), e, apesar de apresentar algumas particularidades dependendo da matéria-prima em questáo (como adiçóes ou diferentes temperaturas de cozimento do gráo ou cereal, por exemplo), tem como base a mesma linha de processo.

A partir disto, este projeto teve como justificativa atender o desejo do consumidor por "leites" vegetais de diversos sabores e com uma maior variedade de preços nas regiôes de Pelotas e Porto Alegre-RS. No contexto, o projeto objetivou avaliar, técnica e economicamente, a viabilidade da instalação de uma agroindústria para processar extrato vegetal de noz pecá e amendoim, saborizados.

\section{MATERIAL E MÉTODOS}

Como se trata de uma proposta de produto novo, é necessário analisar o mercado, testar formulaçóes e estas com o público consumidor através de análise sensorial.

Os dados primários para este projeto foram coletados através de questionário aplicado em redes sociais, com estrutura composta por 11 questóes fechadas e abertas, numeradas sequencialmente. Este questionário objetivou investigar a percepção de consumidores e possíveis consumidores de "leite vegetal" quanto a este segmento de mercado, bem como seus hábitos de consumo e nível de interesse em novos produtos desta linha. O tamanho da amostra foi baseado em SEBRAE (2013), com 96 entrevistados, com um erro amostral de $\pm 10 \%$.

Nesta pesquisa, em complemento aos dados primários coletados através do questionário, utilizaramse dados disponibilizados pelo Instituto Brasileiro de Geografia e Estatística (IBGE, 2016a, 2016b), IBOPE e FBG, que foram trabalhados como dados secundários, conforme metodologia de Ellram e Tate (2016). Levando em consideração a frequência de consumo de extrato vegetal declarada pelo consumidor na pesquisa realizada, combinada com dados secundários coletados, estimou-se a capacidade de produção diária deste empreendimento. Considerou-se a porção de $200 \mathrm{~mL}$ (1 copo) de "leite vegetal" como sendo a quantidade diária consumida. Por fim, determinou-se que a agroindústria irá atender a uma parcela de $30 \%$ dos possíveis clientes consumidores de "leite vegetal". Para a produção dos "leites" de amendoim e noz pecá, foi realizado um teste de formulação no qual utilizouse água potável, potes de vidro, filtro (pano de algodão de malha fina), liquidificador e jarra elétrica, segundo metodologias de Albuquerque et al. (2015), Bento et al. (2012) e Felberg et al. (2009). Com base na receita testada em laboratório, realizou-se o balanço de massa deste projeto.

A análise sensorial ocorreu em junho de 2017, no saguão principal do Centro de Engenharias da Universidade Federal de Pelotas e teve 100 julgadores.

Como o público não era familiarizado/acostumado com o sabor original do produto, optou-se pela saborização dos "leites" de amendoim e noz pecá com achocolatado e/ou cacau, açúcar (quando o cacau foi utilizado), essência de baunilha e goma xantana.

Foram usadas fichas de teste de análise sensorial, com escala hedônica verbal estruturada, com nove pontos (Figura 1) em julgadores não treinados, que aleatoriamente provaram as duas amostras propostas, baseados em Freitas (2004). Optou-se por informar 
sobre o tipo de extrato vegetal por serem produtos com potencial de causar alergia em algumas pessoas.

As duas amostras foram codificadas com três dígitos aleatórios, oferecidas em copinhos plásticos com o respectivo código e a ordem em que os provadores testavam cada uma delas foi sorteada.

\section{TESTE DE ACEITABILIDADE}

Instruçôes: Você está recebendo duas amostras de extrato vegetal: um de amendoim e outro de nozes. Avalie cada uma das amostras codificadas e use a escala abaixo para indicar o quanto você gostou ou desgostou de cada amostra.

9- gostei muitíssimo

8- gostei muito

7- gostei modera-

damente

6- gostei ligeira-

mente

5- nem gostei/nem $\quad \mathrm{N}^{\circ}$ Amostra $\quad$ Valor (1 a 9)

desgostei

4- desgostei ligeira-

mente

3- desgostei mod-

eradamente

2- desgostei muito

1- desgostei muitís-

simo

Comentários:

Figura 1. Ficha de avaliação sensorial com escala hedônica, utilizada no teste de aceitação dos atributos da bebida à base de extratos vegetais

Os dados foram computados para estabelecer a melhor formulação e conhecer a aceitação desse produto. Para que o produto aqui proposto satisfaça adequadamente o cliente, se utilizou uma adaptação da metodologia proposta por Garvin (1992) para investigar as necessidades, explícitas ou não, do cliente, as chamadas "Oito Dimensōes da Qualidade de Garvin" (SUAREZ, 2015). Como facilitador devem-se escolher os requisitos capazes de melhor atingir o público-alvo, logo, para o produto aqui proposto, extrato vegetal, o foco foi restrito para os requisitos: desempenho, características, conformidade e confiabilidade.
Também foram orçados todos os equipamentos necessários para a produção do extrato vegetal, obra civil e demais gastos.

Para o financiamento deste projeto optou-se pelo percentual de $50 \%$ do valor investido, ou seja, o investidor deve ter à disposiçáo metade do valor a ser investido e obter o restante através de outro financiamento. A taxa de juros considerada foi de $12,8 \%$ ao ano.

Nestas condiçôes, foi realizada a análise econômica do projeto, para um horizonte de planejamento de 10 anos, através dos índices econômicos financeiros: VPL (Valor Presente Líquido), TIR (Taxa Interna de Retorno), TIRm (Taxa Interna de Retorno Modificada), payback (tempo de retorno do capital investido) e TMA (Taxa Mínima de Atratividade), considerada para este projeto $10 \%$, de acordo com Buarque (1991).

Os indicadores acima mencionados foram analisados de acordo com três cenários diferentes.

O cenário 1 considera para a produção total, todas as embalagens novas e o preço de venda: extrato vegetal de amendoim $\mathrm{R} \$ 8,00 / \mathrm{L}$, extrato vegetal de noz pecã $\mathrm{R} \$ 20,00 / \mathrm{L}$, farinha de amendoim $\mathrm{R} \$ 13,54 / \mathrm{kg}$ e farinha de noz pecã $\mathrm{R} \$ 56,92 / \mathrm{kg}$.

O cenário 2 considera a produçáo total com os mesmos preços do cenário 1 , porém com $50 \%$ das embalagens com retorno à agroindústria.

O cenário 3 considera a produção total diária, todas as embalagens novas, porém os valores dos extratos vegetais alterados, considerando o valor que o consumidor está disposto a pagar (conforme pesquisa de mercado realizada): extrato vegetal de amendoim $\mathrm{R} \$ 5,00 / \mathrm{L}$ e extrato vegetal de noz pecã $\mathrm{R} \$ 8,00 / \mathrm{L}$.

\section{RESULTADOS E DISCUSSÃO}

Para que os extratos vegetais de noz pecá e de amendoim atinjam o seu objetivo de ser identificados por sua originalidade e atendam às expectativas do cliente em aspectos de função e sabor, os testes e análise sensorial foram essenciais, pois maximizaram as chances de sucesso do produto.

As análises ocorreram em dois dias. No primeiro dia, foram utilizados os ingredientes achocolatado e 
goma xantana nas receitas, sendo as bebidas servidas logo após o preparo em laboratório (ainda mornas, pelo uso de água quente no processo de trituração) e não tendo tido um efeito aparente da goma xantana na sua estabilização. No segundo dia, as bebidas haviam sido preparadas no dia anterior e, como não sofreram o processo de pasteurização, foram armazenadas na geladeira e servidas geladas. Também foram preparadas com a utilização de goma xantana, porém com cacau em pó e açúcar (a essência de baunilha, assim como a goma xantana, foi ingrediente comum nos dois dias de preparação). Houve uma preferência geral pelas bebidas servidas no segundo dia de análise sensorial, indicando uma preferência pela utilizaçáo de cacau em pó e açúcar no processo de preparação e o consumo da bebida gelada.

O extrato vegetal de amendoim foi o que teve maior nível de aceitabilidade, considerando as 100 pessoas que provaram as amostras, tendo atingindo uma média de 8 (classificado como "gostei muito" dentro da metodologia de análise sensorial), enquanto o extrato vegetal de noz pecá teve uma média de 7,5 (estando classificado entre "gostei moderadamente" e "gostei muito"). Além disso, muitos dos entrevistados comentaram que as bebidas poderiam ser mais "encorpadas" ou "grossinhas".

Vale ressaltar que, durante o teste de receitas, algumas amostras foram separadas para serem observadas ao longo de alguns dias, para análise visual da estabilidade do produto (separação em fases ou não) e do período de validade. Separaram-se amostras da receita básica, sem a adição dos ingredientes de saborização, com goma xantana (CG) e sem goma xantana (SG). Como o extrato vegetal não foi pasteurizado, teve uma durabilidade máxima de três dias na geladeira, tendo "coalhado" após este período. A adição de goma xantana não produziu efeitos favoráveis no "leite" de nozes, tendo, ao invés de estabilizado o produto, o separado em fases. No "leite de amendoim", a adição ou não da goma xantana não provocou diferenças visuais significativas no produto (Figura 2).

Para aumentar a durabilidade deste produto teria que ser utilizada uma embalagem do tipo longa vida ou mantê-lo sob refrigeração.
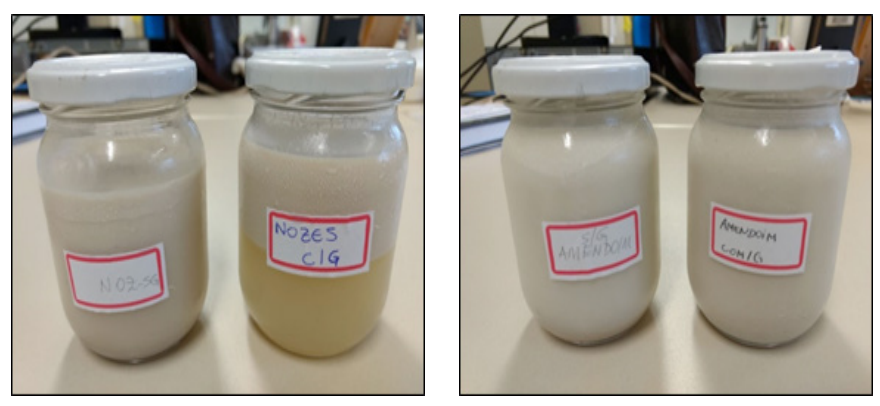

Figura 2. Análise sensorial de "leite vegetal" realizada no CEng da UFPel

Com um total de 294 respostas coletadas na pesquisa com os consumidores via internet, foram filtradas 182 de entrevistados com residência localizada somente em Pelotas ou Porto Alegre. Embora se tenha tomado uma amostra calculada, ela foi direcionada ao público em geral, e não somente ao público vegetariano, vegano ou com restrição de consumo de lactose que estão mais acostumados a consumir este tipo de produto. Acredita-se que o público em geral, compare o extrato vegetal com leite de vaca. Porém, mesmo assim o público em geral teve boa aceitabilidade do produto, mostrando que ele estava próximo do leite de vaca e estima-se que o público de veganos, vegetarianos e intolerantes se comportem da mesma forma.

Para se atender 30\% dos possíveis clientes há de se produzir 78,53 L/dia. Tendo em vista o movimento e beneficiamento da economia local, decidiu-se por produzir, primeiramente, extratos vegetais de amendoim e noz pecã, que são matérias-primas cultivadas na região sul do Brasil. Como estas matériasprimas tiveram a mesma parcela de interesse perante os entrevistados, será produzida metade da demanda diária de extrato vegetal de amendoim e metade da demanda diária de extrato vegetal de nozes, ou seja, 39 L/dia de cada tipo de extrato.

Considerando-se que uma receita de $140 \mathrm{~g}$ de nozes mais $3 \times 240 \mathrm{ml}$ de água rende $650 \mathrm{ml}$ de "leite de nozes", e $140 \mathrm{~g}$ de amendoim mais $4 \times 240 \mathrm{ml}$ de água rende $800 \mathrm{ml}$ de "leite de amendoim", serão necessárias, respectivamente, 60 receitas de "leite de noz pecâ" e 48,75 receitas de "leite de amendoim" para produzir $39 \mathrm{~L} /$ dia.

A partir destas quantidades, foi confeccionado o fluxograma com balanço de massa apresentado na Figura 3, referindo-se ao processo diário de produção de extrato de amendoim e noz pecá, que ocorre em 
duas diferentes linhas de processo. O resíduo do processo passará por secagem, transformando-se assim em farinha de amendoim e de noz pecá, que será embalada em sacos de plástico selados à vácuo para comercialização.

Para o processamento dos extratos vegetais de noz pecã e amendoim, dois dos processos, trituração e separaçáo de insolúveis, ocorrerão em máquina extratora de "leite vegetal", projetada especialmente para esta agroindústria. $\mathrm{O}$ aquecimento da água utilizada no processo de trituração também ocorre nesta máquina, através de resistência elétrica.

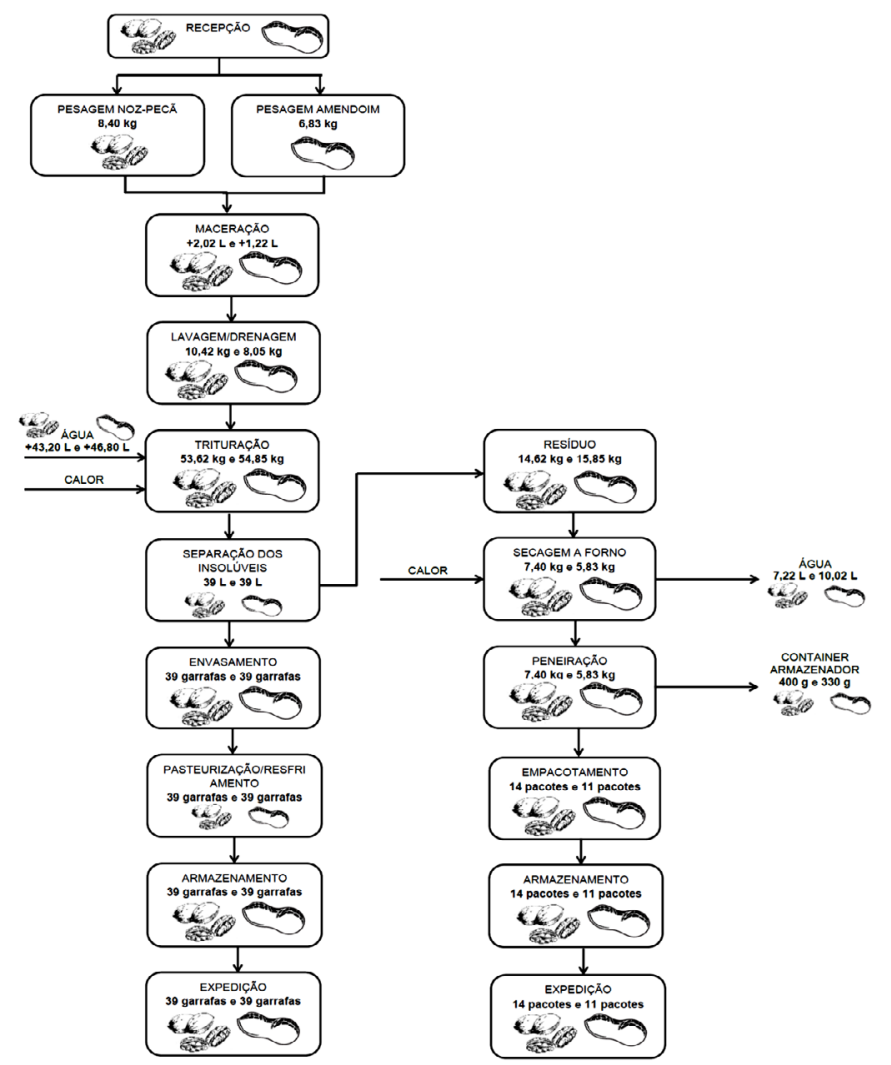

Figura 3. Fluxograma e balanço de massa diário de produção de extratos vegetais de amendoim e noz pecã

Existem diferentes tipos de embalagens de extrato vegetal no mercado: vidros, sacos plásticos e multicamada, que precisam seguir a RDC No 218/2005 e a RDC No 272/2005, da ANVISA. Para este trabalho foram propostas embalagens de vidro, atrativas, do tipo pronto para beber, com apelo de marketing para o produto.

Esta agroindústria necessitará de dois funcionários e um gerente para execução de todas as tarefas.

A Tabela 1 apresenta os resultados da análise de viabilidade econômica dos cenários através dos índices de VPL, TIR, TIRm e payback.

Os cenários 1 e 2 foram considerados viáveis, pois apresentaram TIR maior que TMA, ou seja, possuem um retorno maior do que aquele que seria obtido em um investimento do capital no mercado financeiro.

O cenário 3 apresentou VPL negativo, sendo, portanto, inviável, provavelmente devido ao não retorno de embalagens e aos baixos preços praticados para o extrato vegetal.

A comparação dos três cenários com relação ao tempo de retorno do investimento (payback) mostra que o cenário com menor tempo de retorno é o mais viável (4 anos).

Tabela 1-Índices econômico-financeiros dos cenários estudados

\begin{tabular}{cccc}
\hline Índices & Cenário 1 & Cenário 2 & Cenário 3 \\
\hline $\begin{array}{c}\text { TMA } \\
(\%)\end{array}$ & 10 & 10 & 10 \\
VPL & $1.173 .692,012$ & $790.096,19$ & $-1.017 .781,35$ \\
$(\mathrm{R} \$)$ & & & \\
TIR $(\%)$ & 63,88 & 37,56 & - \\
TIRm & 39,31 & 26,02 & - \\
$(\%)$ & & & \\
$\begin{array}{c}\text { Payback } \\
\text { (anos) }\end{array}$ & 4 & 6 & 11 \\
\hline
\end{tabular}

\section{CONCLUSÃO}

A amostra de maior preferência foi o extrato vegetal de amendoim, servido gelado, saborizado com cacau em pó e açúcar, classificado pelos julgadores como "gostei muito".

Concluiu-se que a adição de goma xantana não produziu efeitos favoráveis no "leite de nozes", tendo, ao invés de estabilizado o produto, o separado em fases. No "leite de amendoim", a adição ou não da goma xantana não provocou diferenças visuais significativas no produto.

Este projeto de relativamente baixo custo é uma oportunidade para se empreender nas cidades de Pelotas e Porto Alegre, visando a um mercado consumidor como alternativa para o leite de vaca, principalmente, para veganos, vegetarianos, intolerantes à lactose e alérgicos à proteína do leite.

As simulaçôes de análise econômica demonstraram 
que a agroindústria em questão mostra-se viável perante a duas possibilidades de cenários. $\mathrm{O}$ cenário que ilustra a política de reutilização das embalagens, além de trazer benefícios ecológicos pode trazer benefícios tanto para a agroindústria como para o consumidor, pois há redução nos custos de compra de embalagens para o empreendimento e possível redução no preço do produto para o consumidor.

\section{LITERATURA CITADA}

ABRAS.ASSOCIAÇÃOBRASILEIRADESUPERMERCADOS (São Paulo) (Ed.). Demanda por produtos vegetarianos ainda é maior que a oferta no Brasil. 2015. Disponível em: <http:// www.abrasnet.com.br/clipping. php?area $=1 \&$ clipping $=51257$ > . Acesso em: 24 mai. 2017.

ALBUQUERQUE, E.M.B.; ALMEIDA, F.A.C.; GOMES, J.P.; ALVES, N.M.C.; SILVA, W.P. Production of "peanut milk" based beverages enriched with umbu and guava pulps. Journal of The Saudi Society of Agricultural Sciences, Riade, v.14, n.1, p.6167, jan. 2015. Disponível em: <http://dx.doi.org/10.1016/j. jssas.2013.07.002>. Acesso em: 29 mai. 2017.

BENTO, R.S.; ESCAPIM, M.R.S.; AMBROSIO-UGRI, M.C.B. Desenvolvimento e caracterização de bebida achocolatada à base de extrato hidrossolúvel de quinoa e de arroz. Revista do Instituto Adolfo Lutz, São Paulo, v.71, n.2, p.317-323, 2012. Disponível em: <ses.sp.bvs.br/lildbi/docsonline/ get.php?id=3827>. Acesso em: 29 mai. 2017.

BRASIL. ANVISA. Agência Nacional de Vigilância Sanitária. Resoluçáo CNNPA No 12, de 15 de setembro de 2000b. Regulamento Técnico Para Fixação de Identidade e Qualidade de Leite de Coco. [s.i.], Disponível em: <http://www.anvisa.gov. br/ anvisalegis/resol/2000/83_00rdc.htm>. Acesso em: 29 mai. 2017.

BRASIL. ANVISA. Agência Nacional de Vigilância Sanitária. Resolução RDC No 91, de 18 de outubro de 2000a. Ementa Náo Oficial: Aprova o Regulamento Técnico para Fixação de Identidade e Qualidade de Alimento com Soja. Disponível em: $<$ http://www.saude.rj.gov.br/comum/code/ MostrarArquivo. php?C=MjI0NA $>$. Acesso em: 29 mai. 2017.

BRASIL. ANVISA. Agência Nacional de Vigilância Sanitária. Resolução - RDC No 218, de 29 de julho de 2005. Regulamento Técnico de Procedimentos Higiênico-Sanitários para Manipulação de Alimentos e Bebidas Preparados com Vegetais. Brasília: D.O.U. 01/08/2005.

BRASIL. ANVISA. Agência Nacional de Vigilância Sanitária. Resolução - RDC No 272, de 22 de setembro de 2005. Regulamento Técnico para Produtos de Vegetais, Produtos de Frutas e Cogumelos Comestíveis. Brasília: D.O.U. 23/09/2005. BUARQUE, C. Avaliação econômica de projetos: uma apresentação didática. Rio de Janeiro: Campus, 1991.

ELLRAM, L.M.; TATE, W.L. The use of secondary data in purchasing and supply management (P/SM) research.European Journal of Purchasing \& Supply Management, [s.i.], v.22, n.4, p. 250-254, dez. 2016. Disponível em: <https://doi.org/10.1016/j. pursup.2016.08.005>. Acesso em: 27 mai. 2017.

EMBRAPA. Empresa Brasileira de Pesquisa Agropecuária. Manual de produçáo de extrato de soja para agroindústria de pequeno porte. 65.ed. Rio de Janeiro: Embrapa, 2005. 12p. Disponível em: $\quad<h t$ tps://www.embrapa.br/busca-de-publicacoes/-/ publicacao/888495/manual-de-producao-de-extrato-de-soj>. Acesso em: 29 mai. 2017.

FBG. FEDERAÇÃO BRASILEIRA DE GASTROENTEROLOGIA (São Paulo). Intolerância à lactose. Disponível em: <http://www.fbg.org.br/ Conteudo/2182/0/ Intolerância-à-Lactose>. Acesso em: 28 mai. 2017.

FELBERG, I.; ANTONIASSI, R.; DELIZA, R.; FREITAS, S.C.; MODESTA, R.C.D. Soy and Brazil nut beverage: processing, composition, sensory, and color evaluation. Ciência e Tecnologia de Alimentos, Campinas, v.29, n.3, p.609-617, jul. 2009. Disponível em: <http://dx.doi.org/10.1590/S0101$20612009000300024>$. Acesso em: 29 mai. 2017.

FREITAS, M.Q. Análise sensorial de alimentos. Universidade Federal Fluminense, Niterói. Disponível em: <ftp://ftp.sp.gov.br/

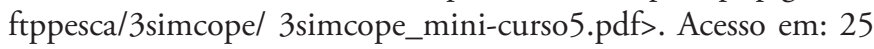
abr. 2017.

GARVIN, D.A. Gerenciando a qualidade: a visão estratégica e competitiva. [s.i.]: Qualitymark, 1992. 357p.

GOOGLE TRENDS. Veganismo: termo de pesquisa. 2017. Disponível em: <https://trends.google.com.br/trends/ explore?geo=BR\&q=veganismo $>$. Acesso em: 28 mai. 2017.

IBGE. INSTITUTO BRASILEIRO DE GEOGRAFIA E ESTATÍSTICA. Rio Grande do Sul - Pelotas: população estimada 2016. 2016a. Disponível em: <http://cod.ibge.gov.br/3D5>. Acesso em: 27 mai. 2017.

IBGE. INSTITUTO BRASILEIRO DE GEOGRAFIA E ESTATÍSTICA. Rio Grande do Sul - Porto Alegre: populaçáo estimada 2016. 2016b. Disponível em: <http://cod.ibge.gov. br/6L0>. Acesso em: 27 mai. 2017.

IBOPE. INSTITUTO BRASILEIRO DE OPINIÃO PÚBLICA E ESTATÍSTICA (Brasil) (Ed.). Dia mundial do vegetarianismo: 8\% da populaçáo brasileira afirma ser adepta do estilo. 2012. Disponível em: <http://www.ibope.com.br/pt-br/noticias/ paginas/dia-mundial-do-vegetarianismo-8-da-populacaobrasileira-afirma-ser-adepta-ao-estilo.aspx $>$. Acesso em: 24 mai. 2017.

STALL, S.; ADAMS, G. Can almond milk be called milk? Journal of Renal Nutrition, [s.i.], v.27, n.3, p.15-17, mai. 2017. Disponível em: <https://doi.org/10.1053/ j.jrn.2017.03.002>. Acesso em: 28 mai. 2017.

SUAREZ, G. David A. Garvin e as oito dimensōes da qualidade por Gregório Suarez. 2015. Disponível em: <https://qualityway. wordpress.com/ 2015/08/18/david-a-garvin-e-as-oitodimensoes-da-qualidade-por-gregorio-suarez-parte-1/>. Acesso em: 27 mai. 2017.

SVB. SOCIEDADE VEGETARIANA BRASILEIRA (São Paulo) (Ed.). Mercado vegetariano: estimativa da porcentagem de vegetarianos e veganos no Brasil. 2016. Disponível em: <http:// www.svb.org.br/vegetarianismo1/mercado-vegetariano>. Acesso em: 24 mai. 2017. 